\title{
Análise da Passagem da Célula Vermelha do Sangue Através de Poros Cilíndricos
}

\author{
J.J. ROSSETTO ${ }^{1}$ P.J. ABATTI ${ }^{2}$ Programa de Pós-Graduação em Engenharia \\ Elétrica e Informática Industrial(CPGEI), CEFET-PR, 80230-901 Curitiba, PR, \\ Brasil.
}

Resumo. São deduzidas expressões relacionando a área da superfície da membrana e o volume das células vermelhas do sangue (cvs) com os raios e comprimentos (mínimos e máximos) dos poros, da distância entre eles e do número $\mathrm{n}$ de poros cilíndricos, na qual a célula é capaz de transpô-los conjuntamente. Destas equações, conclui-se que aumentando-se o número de poros restringe-se a passagem das cvs através dos mesmos, além de servir como base para um possível modelo fisiológico do fenômeno de filtração dos glóbulos vermelhos.

\section{Introdução}

Em trabalhos recentes vem sendo discutida a determinação da habilidade da célula vermelha do sangue (cv) do corpo humano para transpor um e dois poros cilíndricos [1], [4]. A forma física que o glóbulo vermelho assume ao atravessar poros cilíndricos, introduz novos problemas em biomatemática, uma vez que análises físicas e matemáticas são utilizadas para se derivar fórmulas que relacionam o volume e a área da superfície da membrana da cv com os raios e os comprimentos dos poros envolvidos.

O principal objetivo deste trabalho é analisar a passagem da célula por um número qualquer de poros curtos de dimensões iguais, coaxiais, e separados por uma mesma distância fixa d. Deduzir-se-á as relações entre o volume e a área de superfície da membrana da cv (dados que caracterizam a cv), com as dimensões dos poros cilíndricos (raio e comprimento), distância entre os poros e o número $\mathrm{n}$ de poros, observando-se as conseqüências decorrentes na travessia da cv ao se aumentar o número $\mathrm{n}$ de poros.

Inicialmente as características da cv humana serão apresentadas. Em seguida, a análise da passagem do glóbulo vermelho por um e por dois poros será revisada. Finalmente, as análises apresentadas serão generalizadas para o caso de $\mathrm{n}$ poros.

\footnotetext{
${ }^{1}$ Departamento de Matemática da UFPR e Doutorando em Eng. Biomédica. E-mail: jjross@mat.ufpr.br

${ }^{2}$ Professor Doutor do CPGEI/CEFET-PR.
} 


\section{A célula vermelha do sangue}

A cv humana sobre condições normais em repouso, em um corte transversal, se apresenta na forma de disco bicôncavo com diâmetro médio de aproximadamente $8 \mu m$ e espessura aproximada de $2 \mu m$ (Figura 1 ).

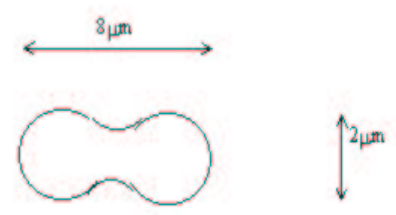

Figura 1: Esboço de uma célula vermelha do sangue

No entanto, à medida que envelhece, a cv vai perdendo área de superfície da membrana e volume. Porém, este é um processo lento, permitindo considerar o tamanho dessas células estável durante um curto período de tempo (um dia, por exemplo). Na Tabela I, se indica a área e o volume das células vermelhas conforme a idade.

Tabela I - Dimensões de cvs classificadas por idade.

\begin{tabular}{|l|l|l|}
\hline Tipo de cv quanto à idade & Área $\left(\mu m^{2}\right)$ & Volume $\left(\mu m^{3}\right)$ \\
\hline cv jovem & 148 & 98.1 \\
\hline cv típica & 134 & 89.8 \\
\hline cv idosa & 118 & 78 \\
\hline
\end{tabular}

A cv é formada de um volume (V) líquido, contendo principalmente água, eletrólitos e hemoglobina, sendo livre de núcleo e organelas. A sua membrana possui características de um líquido bidimensional (pode assumir em princípio qualquer forma, mas preserva a área de superfície (A)), pois possui uma forte resistência para dilatação de área (módulo de expansão da área da membrana de aproximadamente $450 \mathrm{mN} / \mathrm{m}$ ) e apresenta uma pequena resistência a deformação da membrana para área constante (aproximadamente $6-9 \mathrm{mN} / \mathrm{m}$ ) e módulo de curvatura estimada em $2 \cdot 10^{-19} \mathrm{~N} / \mathrm{m}[2]$ e [3]. Deste modo, a célula pode ser modelada como um envólucro maleável não preenchido totalmente (caso fosse preenchido completamente assumiria o formato esférico) de volume constante envolvido por uma membrana de área da superfície constante com alta deformabilidade [1], [2], [3] e [4].

\section{Passagem da cv por um poro cilíndrico}

Das características da cv supra citadas pode-se inferir que, para um dado poro de raio $r$ e comprimento $L$, esta vem a assumir na oclusão um formato de halteres 
assimétrico (figura geométrica que apresenta a menor área de superfície para um dado volume, nestas condições (Figura 2). Assim, é possível expressar a área de superfície $(A)$ e o volume $(V)$ da cv, assumindo que esta é constituída de um cilindro de raio r e comprimento $L$ e duas esferas de raios $R_{L}$ e $R_{R}$ (subtraídas as calotas esféricas sobrepostas). Tem-se,

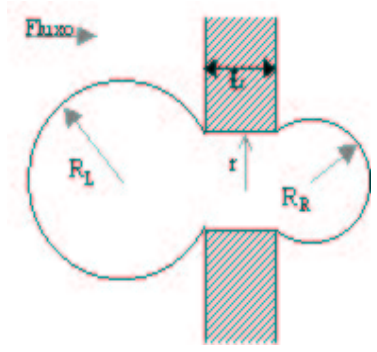

Figura 2: Ilustração de uma cv atravessando um poro curto

$$
\begin{gathered}
A=2 \pi r L+4 \pi R_{L}^{2}-2 \pi R_{L} h_{L}+4 \pi R_{R}^{2}-2 \pi R_{R} h_{R} ; \\
V=\pi r^{2} L+\frac{4}{3} \pi R_{L}^{3}-\frac{1}{3} \pi h_{L}^{2}\left(3 R_{L}-h_{L}\right)+\frac{4}{3} \pi R_{R}^{3}-\frac{1}{3} \pi h_{R}^{2}\left(3 R_{R}-h_{R}\right),
\end{gathered}
$$

onde $h_{L, R}$ denotam as alturas das entradas das esferas no poro do lado esquerdo e direito (os raios das calotas esféricas sobrepostas), respectivamente.

Da Figura 2, pode-se destacar os triângulos retângulos de lados $\left(R_{L}, r, R_{L}-h_{L}\right)$ e $\left(R_{R}, r, R_{R^{-}} h_{R}\right)$, donde, $R_{L, R}=\frac{r^{2}+h_{L, R}^{2}}{2 h_{L, R}}$.

Substituindo estas duas últimas relações acima em (3.1) e (3.2), pode-se escrever

$$
\begin{gathered}
A=2 \pi r L+\pi r^{2}\left(\frac{r^{2}}{h_{L}^{2}}+\frac{r^{2}}{h_{R}^{2}}+2\right) ; \\
V=\pi r^{2} L+\frac{\pi r^{4}}{6}\left(\frac{r^{2}+3 h_{L}^{2}}{h_{L}^{3}}+\frac{r^{2}+3 h_{R}^{2}}{h_{R}^{3}}\right) .
\end{gathered}
$$

A célula é capaz de atravessar o poro somente se a derivada de $\mathrm{h}_{L}$ em relação a $\mathrm{h}_{R}$, em ambas as equações (3.3) e (3.4), são pelo menos iguais [1]. Fazendo-se os cálculos deduz-se as condições de contorno, $h=h_{L}=h_{R} \leq r$. Isto é, a cv somente transpõe os poros se atingir uma forma de halteres simétrico. Substituindo em (3.3) e (3.4), após eliminar h encontra-se

$$
L=r\left[\frac{A}{2 \pi r^{2}}-1-\left(\sqrt[3]{3\left(\frac{V}{\pi r^{3}}-\frac{A}{2 \pi r^{2}}\right)+2}+1\right)^{2}\right],
$$

que relaciona o raio mínimo do poro/comprimento máximo na qual a cv é capaz de atravessar, indicando que, para poros curtos $(r>h)$, ambos, raio e comprimento, 
são mutuamente dependentes. Para poros longos $(r=h), r$ independe de $L$, pois obtém-se simplesmente, $r^{3}-\frac{3 A r}{4 \pi}+\frac{3 V}{2 \pi}=0$.

A aplicação desses resultados para projeto e especificação de filtros é direta, e a Figura 3 fornece valores de $L$ e $r$ para os quais uma cv típica atravessa ou não um dado poro curto [1].

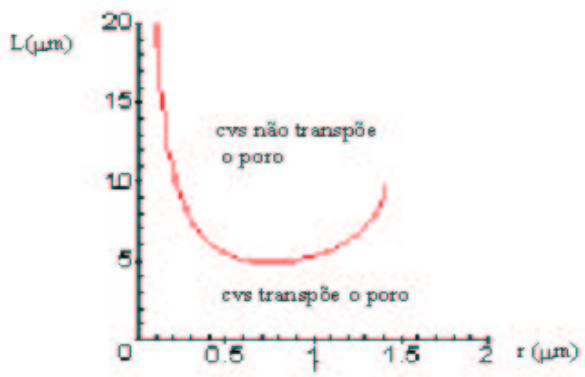

Figura 3: L em função de r para uma cv típica

\section{Passagem da cv por dois poros cilíndricos}

Tomando-se o caso de dois poros de raios e comprimentos iguais a $(r, L)$, se-parados por uma distância d, Figura 4 e considerando-se os poros paralelos e coaxiais, assegura-se, por razões geométricas, que a cv toma na parte central um formato esférico (a esfera gerada por revolução sobre o eixo coaxial pela circunferência circunscrita a um retângulo). Assim, a célula se constitui de três esferas e dois cilindros (menos as calotas esféricas de raios iguais as alturas das entradas das esferas nos poros). Devido a unicidade da esfera central, tem-se que esse formato esférico permanece constante durante o fluxo da célula, enquanto existe área e volume suficiente entre os dois poros. Denotando os raios das esferas por $R_{L}, R_{M}$ e $R_{R}$, escreve-se as fórmulas da área e do volume da cv. Tem-se,

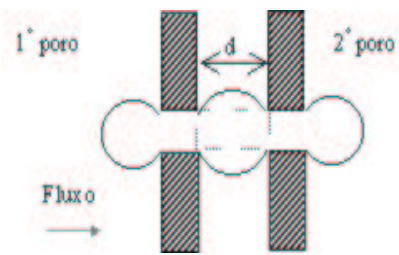

Figura 4: Uma cv transpondo dois poros curtos

$$
\begin{aligned}
A= & 2 \pi r L+2 \pi r L+4 \pi R_{L}^{2}-2 \pi R_{L} h_{L}+4 \pi R_{R}^{2}-2 \pi R_{R} h_{R} \\
& +4 \pi R_{M}^{2}-2 \pi R_{M} h_{1}-2 \pi R_{M} h_{1} ;
\end{aligned}
$$




$$
\begin{aligned}
V= & \pi r^{2} L+\pi r^{2} L+\frac{4}{3} \pi R_{L}^{3}-\frac{1}{3} \pi h_{L}^{2}\left(3 R_{L}-h_{L}\right)+\frac{4}{3} \pi R_{R}^{3} \\
& -\frac{1}{3} \pi h_{R}^{2}\left(3 R_{R}-h_{R}\right)+\frac{4}{3} \pi R_{M}^{3}-\frac{1}{3} \pi h_{1}^{2}\left(3 R_{M}-h_{1}\right) \\
& -\frac{1}{3} \pi h_{1}^{2}\left(3 R_{M}-h_{1}\right),
\end{aligned}
$$

onde $h_{1}$ é a altura da entrada da esfera central nos poros (o raio das duas calotas esféricas centrais). Outras relações geométricas úteis que destacam-se da Figura 4 são, $R_{L}=\frac{r^{2}+h_{L}^{2}}{2 h_{L}}, R_{R}=\frac{r^{2}+h_{R}^{2}}{2 h_{R}}, R_{M}=\frac{r^{2}+h_{1}^{2}}{2 h_{1}} \mathrm{e}$

$$
R_{M}=\frac{d+h_{1}+h_{2}}{2} .
$$

Substituindo as equações acima adequadamente em 4.1 e 4.2, obtém-se,

$$
\begin{gathered}
A=\pi\left(2 r L+2 r L+\frac{r^{4}}{h_{L}^{2}}+\frac{r^{4}}{h_{R}^{2}}+\frac{r^{4}}{h_{1}^{2}}+2 r^{2}-h_{1}^{2}\right) \\
V=\pi\left[r^{2} L+r^{2} L+\frac{1}{6}\left(\frac{r^{6}}{h_{L}^{3}}+\frac{3 r^{4}}{h_{L}}+\frac{r^{6}}{h_{R}^{3}}+\frac{3 r^{4}}{h_{R}}+\frac{r^{6}}{h_{1}^{3}}+\frac{3 r^{4}}{h_{1}}-3 r^{2} h_{1}-h_{1}^{3}\right)\right] .
\end{gathered}
$$

Para determinar as condições de contorno no caso de dois poros, observa-se, primeiramente, que o par de valores $(r, L)$ devem pertencer à faixa de valores que permite a célula transpor um só poro isoladamente. Evita-se assim, possíveis oclusões já no primeiro poro.

Em seguida, nota-se que para a célula transpor os dois poros, esta deverá realizar uma travessia isolada pelo segundo poro. De fato, como a célula segue o fluxo esquerda-direita e durante a travessia a parte esférica central permanece constante, haverá transferência de área e volume do extremo esquerdo para o extremo direito e isso se segue até o momento em que a cv atinja a situação limite de desprender-se do primeiro poro. Daí, para concluir a travessia a cv realizará uma passagem isolada pelo segundo poro (Figura 5).

Portanto, a primeira condição acima também garante essa passagem isolada pelo segundo poro.

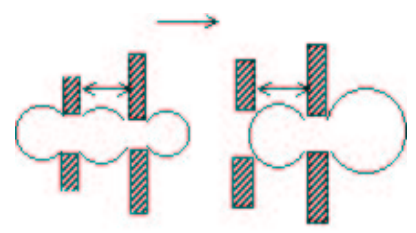

Figura 5: A cv realizará uma travessia isolada pelo segundo poro

Da discussão feita acima segue ainda a forma como a travessia da cv transcorrerá no caso conjunto, mas isso dependerá da distância d entre os poros. 
Se a distância d entre os poros é grande (por exemplo quando a célula pode ser justaposta entre os poros durante a travessia, apenas iniciando o enchimento nos poros), tem-se que a cv transpõe os dois poros isoladamente e a condição de que o par de valores $(r, L)$ pertença à faixa de passagem por um só poro é também suficiente para garantir a travessia da célula. Observa-se que o caso se reduz ao da passagem por um só poro (duas vezes).

Para tratar da travessia conjunta, estima-se d da seguinte forma: considera-se o caso em que o primeiro poro possui medidas que permitem a célula atingir a situação limite de um halteres simétrico em relação a esse poro. Em seguida "tangencia-se" a célula à direita pelo segundo poro, Figura 6 .

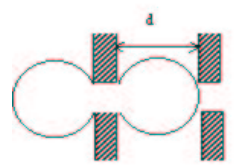

Figura 6: Indica um valor máximo para d

Determina-se assim um valor máximo para d. De fato, qualquer incremento adicional ao valor de d ocasionará uma sobra de área para o volume dado, "murchando" a célula e impedindo que esta atinja o formato esférico entre os poros como deseja-se para se considerar o caso da travessia conjunta. Esse é o valor máximo que será usado para d. Estima-se d observando-se que este é aproximadamente $2 R$ (pela equação 4.3, desprezando-se o pequeno valor de $\mathrm{h}_{1}$ ), onde $R$ é o raio da esfera entre os poros, sendo esta de volume igual a metade do volume da célula (devido à simetria) já subtraído o volume do cilindro (primeiro poro). Tomando o maior poro possível, quase no limite de um poro longo $(r=1.4, L=7.8)$ e o volume de uma cv típica (Tabela I), encontra-se $d \leq 3.4 \mu \mathrm{m}$. Assim,

$$
d=\left[\frac{3}{\pi}\left(V_{c v s}-\pi r^{2} L\right)\right]^{\frac{1}{3}},
$$

onde $V_{c v s}$ é o volume da célula e $(r, L)$ medidas do poro satisfazendo a equação 3.5.

Portanto, já foram estabelecidas as condições para se tratar da travessia conjunta por dois poros sem que haja oclusões em um dos poros individualmente. Porém, as condições acima não são suficientes. Observe-se na fig.7, um caso de oclusão da célula $\left(R_{L}>R_{R}\right)$. Sabe-se que durante a travessia o enchimento esférico entre os poros permanece constante, variando-se apenas as esferas dos extremos dos lados de fora dos poros. Então, pelo mesmo argumento do caso de um só poro, a célula somente conseguirá transpor os poros se atingir a situação limite $R_{L}=R_{R}$, ou seja, formas esféricas simétricas dos lados extremos de fora dos poros. 


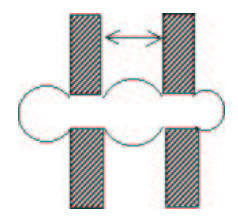

Figura 7: Exemplo de uma oclusão no caso da travessia conjunta da célula por dois poros

A última das três condições acima, $R_{L}=R_{R}$, juntamente com as demais citadas acima, é também suficiente. De fato, as condições $d \leq 3.4 \mu \mathrm{m}$ e as medidas de cada poro dentro da faixa de passagem por um só poro, garantem que não haverá oclusão individual num dos poros e enchimento considerável garantindo tratar-se de travessia simultânea. Daí se a célula atinge a situação limite $R_{L}=R_{R}$ ela continua o fluxo esquerda-direita transferindo área e volume do extremo esquerdo para o extremo direito, permanecendo a esfera central constante, até o limite em que desprende-se do primeiro poro (Figura 5). A partir daí, a célula conclui a travessia com uma passagem individual pelo segundo poro.

Portanto as condições de contorno (necessárias e suficientes) que garantem a passagem da célula por dois poros cilíndricos de raios e comprimentos iguais, conjuntamente, são: (a) $\mathrm{O}$ par de valores $(r, L)$, deve pertencer à faixa de valores que permitem a cv transpor um só poro (Figura 3); (b) $d \leq 3.4 \mu m$ e (c) $R_{L} \leq R_{R}$.

A condição $R_{L}=R_{R}$, nos fornece, como no caso de um só poro, $h=h_{L}=h_{R} \leq$ $r$. Substituindo $h<r$ (mantendo-se com poros curtos) em (4.4) e (4.5), elimina-se a variável $h$, obtendo-se,

$$
\begin{aligned}
& L=\quad \frac{r}{2}\left[\frac{A}{2 \pi r^{2}}-1-\frac{1}{2}\left(\frac{r}{h_{1}}\right)^{2}+\frac{1}{2}\left(\frac{h_{1}}{r}\right)^{2}-(\sqrt[3]{w}+1)^{2}\right] \\
& \text { com } \quad w=3\left(\frac{V}{\pi r^{3}}-\frac{A}{2 \pi r^{2}}\right)+2-\frac{1}{2}\left(\frac{r}{h_{1}}-1\right)^{3}+\frac{1}{2}\left(\frac{h_{1}}{r}-1\right)^{3},
\end{aligned}
$$

onde, $h_{1}=-\frac{d}{2}+\sqrt{r^{2}+\left(\frac{d}{2}\right)^{2}}$.

A equação (4.7) generaliza a equação (3.5). De fato, fazendo-se $d=0$, obtém-se $h_{1}=r$ e substituindo-se na equação (4.7), encontra-se exatamente a equação (3.5) com $2 L$ no lugar de $L$.

\section{Passagem da cv por $\mathbf{n}$ poros de dimensões iguais}

Uma vez estabelecidas as condições de contorno e as fórmulas para os casos de um e dois poros, toma-se como auxílio a passagem por três poros iguais para se observar como o aumento de mais um poro influencia nas condições de contorno e na fórmula explícita de $L$ em função de $r$, generalizando-se logo em seguida para n poros. Considere a Figura 8 abaixo, na qual tem-se três poros de raios e comprimentos iguais a $r$ e $L$ respectivamente e separados por uma mesma distância d. 


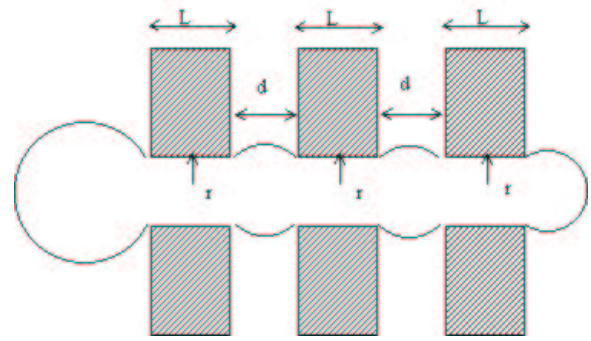

Figura 8: cv atravessando três poros de raios e comprimentos iguais

Tem-se que a cr é constituída de quatro esferas e três cilindros (subtraídas as calotas sobrepostas). Uma vez que as esferas centrais permanecem constantes durante o fluxo, a condição crucial para a travessia da célula é, novamente, que esta atinja formas esféricas simétricas dos lados extremos de fora dos poros. Daí, a célula segue até desprender-se do primeiro poro e em seguida executará uma travessia pelos dois poros seguintes. Faz-se necessário, então, que os pares de valores $(r, L)$ já estejam na faixa de travessia por dois poros, para que a célula conclua a travessia e, também, para não haver oclusão nos dois primeiros poros. Se houvessem quatro poros de dimensões iguais, o mesmo ocorreria, ou seja, a célula realizaria uma travessia por três poros e, indutivamente, se conclui que para a travessia da cv por um número $\mathrm{n}$ de poros, sempre será necessário impor a condição de que os pares de valores $(r, L)$ já pertençam à faixa de valores que garantem a travessia por $(n-1)$ poros. Quanto a distância d entre os poros, esta deverá ser suficientemente pequena para garantir enchimento em todos os meios externos aos poros. Com as dimensões dos poros iguais e também a distância entre eles, estima-se d. Assim, generalizando-se 4.6 para $n$ poros, obtém-se, $d=\sqrt[3]{\frac{6}{n \pi}\left(V_{c v s}-(n-1) \pi r^{2} L\right)}$, onde $V_{c v s}$ é o volume da célula e $(r, L)$ medidas dentro da faixa de passagem da célula por $(n-1)$ poros. No entanto, o interesse principal neste trabalho é deduzir uma fórmula explícita em função de n (do número de poros) e analisar o que o seu aumento ocasiona. Para que o parâmetro d não interfira nos resultados ele é fixado em um valor $(d=2 \mu \mathrm{m}$ por exemplo). Como durante a travessia as partes esféricas centrais permanecem constantes, a cv somente transpõe os poros se atingir simetria nos extremos (esquerdo e direito) do lado de fora dos poros, ou seja, $R_{L}=R_{R}$, o que é equivalente, aplicando-se o mesmo procedimento do caso de um e dois poros (derivando-se as fórmulas da área de superfície e do volume da cv) a $h_{L}=h_{R}=h$.

Portanto as condições necessárias e suficientes que garantem a travessia da célula no caso de n poros são: (a) os pares de valores $(r, L)$ devem pertencer à faixa de valores que garantem a travessia da célula por $(n-1)$ poros; (b) $d \leq 2 \mu \mathrm{m}$ e (c) a célula deve atingir simetria dos lados esquerdo e direito, nos extremos do lado de fora dos poros, $\left(R_{L}=R_{R}\right)$, ou, de forma equivalente, $h_{L}=h_{R}=h$.

Para se explicitar uma fórmula genérica para $n$ poros, se expressa a área da superfície e o volume da cv em função de $n$. Já com as condições de contorno 
substituídas, indutivamente deduz-se, para poros curtos $(h<r)$,

$$
\begin{gathered}
\frac{A}{2 \pi r^{2}}=\frac{n L}{r}+\frac{r^{2}}{h^{2}}+1+\frac{n-1}{2}\left(\frac{r^{2}}{h_{1}^{2}}-\frac{h_{1}^{2}}{r^{2}}\right), \\
\frac{V}{\pi r^{3}}=\frac{n L}{r}+\frac{1}{3}\left(\frac{r^{3}}{h^{3}}+3 \frac{r}{h}\right)+\frac{n-1}{6}\left(\frac{r^{3}}{h_{1}^{3}}+3 \frac{r}{h_{1}}\right)-\frac{n-1}{6}\left(3 \frac{h_{1}}{r}+\frac{h_{1}^{3}}{r^{3}}\right) .
\end{gathered}
$$

Manipulando-se as equações (5.1) e (5.2) elimina-se $h$ obtendo-se,

$$
L=\frac{r}{n}\left[\frac{A}{2 \pi r^{2}}-1-\frac{n-1}{2}\left(\frac{r^{2}}{h_{1}^{2}}-\frac{h_{1}^{2}}{r^{2}}\right)-(\sqrt[3]{w}+1)^{2}\right],
$$

com $w=3\left(\frac{V}{\pi r^{3}}-\frac{A}{2 \pi r^{2}}\right)-\frac{n-1}{2}\left(\frac{r}{h_{1}}-1\right)^{3}+\frac{n-1}{2}\left(\frac{h_{1}}{r}-1\right)^{3}+2$ onde $h_{1}$ é dado por $h_{1}=-\frac{d}{2}+\sqrt{r^{2}+\left(\frac{d}{2}\right)^{2}}$.

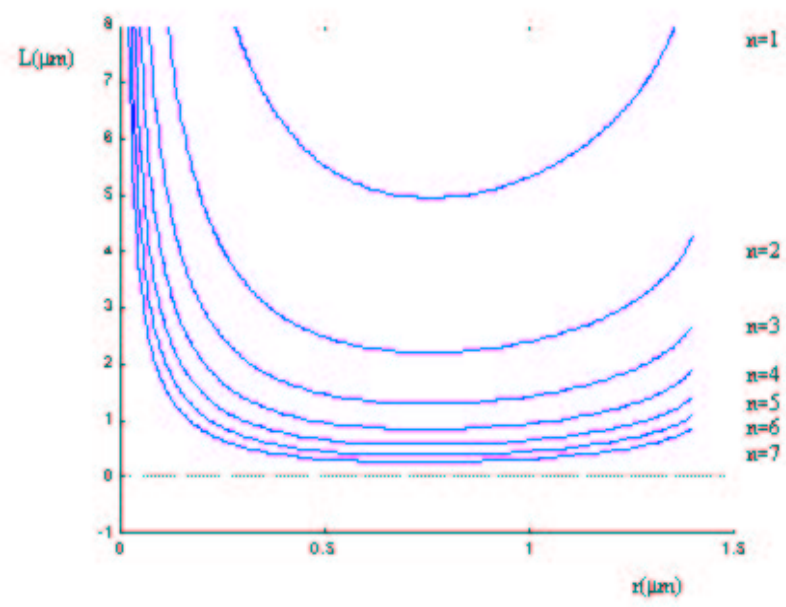

Figura 9: Curvas limite de passagem de uma cv típica quando da passagem conjunta desta por um número $\mathrm{n}$ de poros cilíndricos de dimensões iguais

Pode-se então, esboçar as curvas limite de $L$ em função de $r$ e determinar a faixa de travessia da cv dada. Para uma cv típica (Tabela I) e com distância $d=2 \mu m$ fixa entre os poros, tem-se as curvas limite de passagem da célula para $n=1, n=2$, $n=3, n=4, n=5, n=6, n=7$, Figura 9 .

A Figura 9 indica que a medida em que se aumenta o número de poros se dificulta a passagem da célula vermelha do sangue. 


\section{Conclusões e discussões}

Obteve-se, para um número qualquer de poros curtos cilíndricos de dimensões iguais, uma fórmula explícita do comprimento em função do raio (elementos que caracterizam os poros), relacionados com os dados que caracterizam a célula (área e volume), o número $n$ de poros e da distância entre eles.

Os resultados indicam a possibilidade da construção de um novo tipo de filtro, onde o aumento do número de poros altera a seletividade do mesmo. Observa-se que um aumento no número de poros restringe a faixa de passagem da mesma. Porém, no aspecto econômico esse tipo de filtro é menos vantajoso, quando comparado aos obtidos com um só poro [1] e dois poros [4]. Um ajuste na distância d entre os poros indica um tipo de filtro de menor custo [4].

No entanto, a situação aqui apresentada (da passagem conjunta por uma série de poros cilíndricos) pode ser um caso mais próximo de uma situação real, encontrada em órgãos do corpo humano responsáveis pela seleção dos glóbulos vermelhos (como, por exemplo, o baço). Assim, os resultados aqui expostos contribuem para a modelagem do fenômeno de filtração destas células, o qual na prática é bem mais complexo do que o apresentado em trabalhos recentes sobre o assunto.

Abstract. Expressions relating the red blood cell (rbc) volume and membrane surface area to the pore minimum radius/maximum lenght, the distance between pores and the number which the cell is able to cross simultaneously are derived. From these equations it can be concluded that by increasing the number of pores the rbc's passage is restricted and, in addition, this can be used as a basis for a possible physiological model for the phenomena related to rbc filtration.

\section{Referências}

[1] P.J. Abatti, Determination of the red blood cell ability to traverse cylindrical pores, Transactions on Biomedical Engineering, 44 (1997), 209-212.

[2] E.A. Evans, Membrane mechanics and cell adhesion, Frontiers in Biomechanics, (1986), 3-17.

[3] R.M. Hochmut, "Properties of Red Blood Cells", Handbook of Bioengineering, 12.1-12.17, New York, 1987.

[4] J.J. Rossetto, P.J. Abatti, Determinação da habilidade da célula vermelha do sangue para tranpor dois poros cilíndricos, em "II Congreso Latinoamericano de Ingeniería Biomédica", Havana, 2001. 